\title{
More regulation needed on dermal fillers
}

Caroline Mills, British Association of Oral and Maxillofacial Surgeons (BAOMS) Lead on Aesthetic/Cosmetic Surgery and Consultant Maxillofacial Surgeon at Great Ormond Street Hospital, welcomed the publication on 24 July of new guidance from the Joint Council for Cosmetic Practitioners (JCCP) on the remote prescription of medication for non-surgical cosmetic treatments such as dermal fillers, but said it did not go far enough.

Dr Mills said: 'While BAOMS agrees with the introduction of guidelines for remote prescription of dermal fillers and other medications for high street beauty salon practitioners, we want to see regulation of the industry in line with European Union (EU) rules.

'The new JCCP guidance to curb remote prescribing will provide some protection for patients, but it does not go far enough. In the EU practitioners have to have a medical licence to inject fillers, and we need similar regulation in the UK.

'Even with the new guidelines where the prescriber will assess the patient's suitability for treatment, there is still the risk of serious medical complications because the regulations allow non-medical staff to give non-surgical injectables.'

Dr Mills explained that patients can suffer vascular occlusion, possibly leading to blindness, or severe allergic reactions both of which require emergency medical treatment: 'It's recognising and managing these problems that is so important and where patient safety maybe compromised.'

The NHS faces increasing costs to treat the high street procedures that go wrong. But, without NHS coding for non-surgical

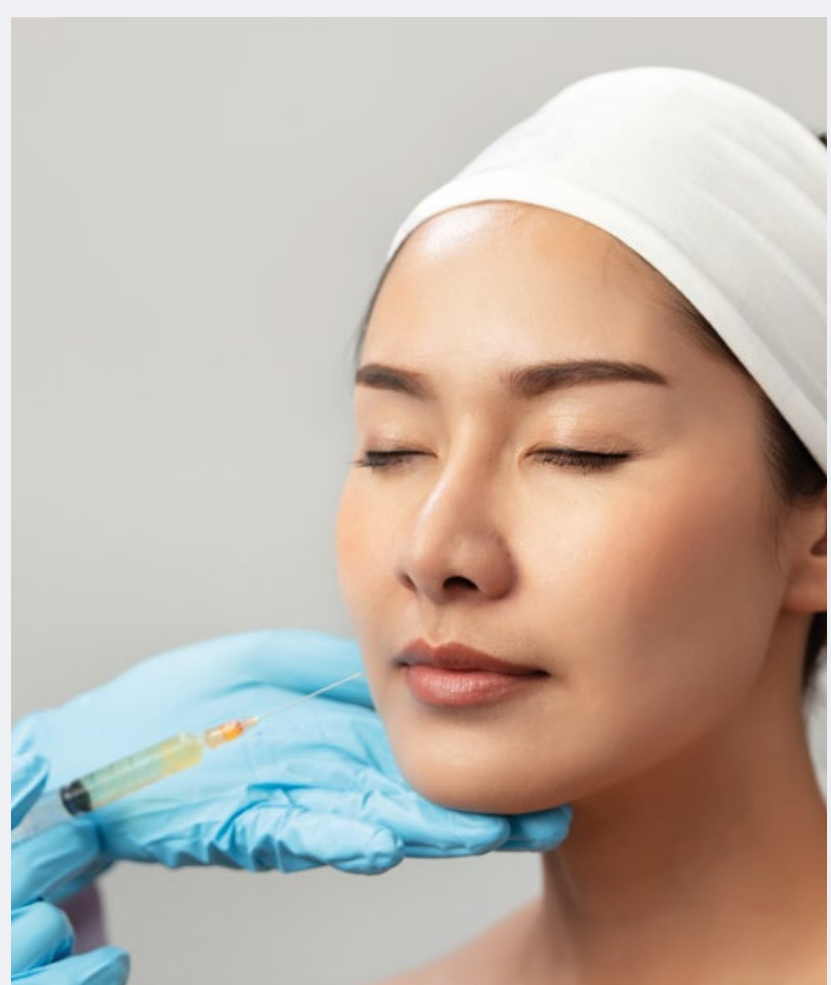

treatment problems the scale of emergency treatment and corrective surgery remains unknown.

'We need regulation in the UK to protect patients properly' said Dr Mills.

\section{BSAD announces its speakers for this September}

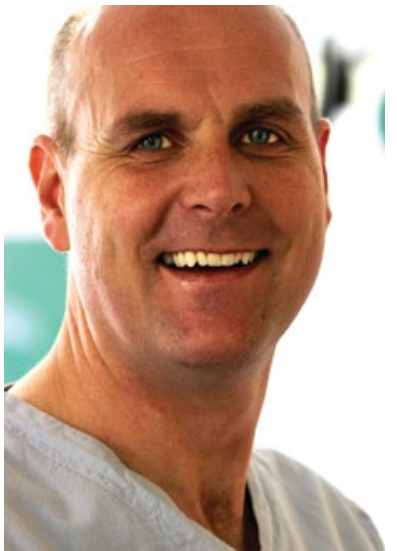

Louis Mackenzie
The British Society for Advanced Dentistry (BSAD) has announced that its annual conference, scheduled to take place in Birmingham on 27-28 September 2019, will feature keynote speakers Professor Iain Chapple, Dr Tif Qureshi and Dr Dipesh Parmar, as well as a hands-on session from Dr Louis Mackenzie (pictured).

The BSAD - a society providing an academic forum for general dental practitioners with postgraduate diplomas - will host its annual conference in the Hotel Du Vin, Birmingham.

The society, formerly known as the British Society for General Dental Surgery (BSGDS), was formed in 1983 and reformed in 2015, when it merged with the Implant Diploma (FGDP) Alumni.

The society now offers opportunities for cross discipline discussion, audit and peer review of provided treatments, as well as opportunities for active training and development of younger graduates who commit to further study.
A delegate place at the event includes attendance at the conference with various speaker and special guest presentations, and a place at the BSAD Gala dinner (on Friday 27 September). Events and tours are also planned for delegates' partners.

Guest presentations at the event include:

- Professor Iain Chapple - Periodontal-systemic links - the truth and nothing but the truth - AND - Peri implantitis - an epidemic?

- Dr Tif Qureshi - Dahl, and Ortho-Restorative Dentistry - What every dentist needs to know...

- Dr Dipesh Parmar - Veneers: Direct Composite vs. Indirect Ceramic.

The Hands-On Session on the morning of 28 September led by Dr Louis Mackenzie will focus on: minimally invasive direct restorative techniques.

BSAD President Dr Nigel Jones said: 'We are delighted to have such a diverse range of expertise from colleagues with a wealth of experience in their respective fields. We also hope to encourage new members of our profession who hold - or are training for - a diploma-level qualification (or higher) and have a commitment to advanced dentistry- to join us.'

For more information on the BSAD, to book tickets to the conference, and for details on how you can become a member, visit: www.bsad.website. 